\title{
Comparison of visual performance of toric vs non-toric intraocular lenses with same material
}

This article was published in the following Dove Press journal:

Clinical Ophthalmology

\author{
Tomofusa Yamauchi' \\ Hitoshi Tabuchi' \\ Kosuke Takase' \\ Zaigen Ohara' \\ Hitoshi Imamura' \\ Yoshiaki Kiuchi ${ }^{2}$ \\ 'Department of Ophthalmology, \\ Tsukazaki Hospital, Himeji, Japan; \\ ${ }^{2}$ Department of Ophthalmology, \\ Hiroshima University, Hiroshima, Japan
}

Correspondence: Tomofusa Yamauch Department of Ophthalmology, Tsukazaki Hospital, 68-I, Waku, Aboshi-ku, Himeji 67I-I227, Japan

Tel +8I 792728555

Fax +8I 792728550

Email t.yamauchi@tsukazaki-eye.net

\begin{abstract}
Aim: We compared the visual performance of toric intraocular lenses (IOLs) and non-toric IOLs made of the same material.

Patients and materials: The subjects included patients implanted with either Acrysof $\mathrm{IQ}^{\circledR}$ toric IOLs (SN6AT3-9) or Acrysof IQ ${ }^{\circledR}$ IOLs (SN60WF) bilaterally. The toric group included 103 patients who were implanted with Acrysof IQ toric IOLs bilaterally. The non-toric group was a corneal astigmatism-matched control group and included 103 patients who were implanted with Acrysof IQ IOLs bilaterally.
\end{abstract}

Results: The uncorrected distance visual acuity was significantly better in the toric group, whereas the uncorrected $50 \mathrm{~cm}$ visual acuity was better in the non-toric group. There was no significant difference in contrast sensitivity (with and without glare) between both the groups. The rate of spectacle dependency for distance vision was significantly lower in the toric group. There were no significant differences between the two groups in all items of the postoperative quality-of-vision questionnaire (25-item Visual Function Questionnaire).

Conclusion: The toric IOLs used in this study reduced spectacle dependency more than the non-toric IOLs and did not compromise the subjective visual function, but the uncorrected $50 \mathrm{~cm}$ vision was worse in toric IOL implanted eyes.

Keywords: cataract, cataract surgery, astigmatism, visual function

\section{Introduction}

In recent years, one of the goals of cataract surgery is to provide better uncorrected visual acuity (VA). Generally, the use of spherical intraocular lenses (IOLs) with appropriate power provides patients without corneal astigmatism good postoperative uncorrected VA. However, previous reports have shown that among the patients in the most prevalent age group for cataract surgery, about $40 \%$ had corneal astigmatism greater than 1.0 $\mathrm{D}$ and about $10 \%$ had astigmatism greater than 2.0 D. ${ }^{1,2}$ For the patients with corneal astigmatism, achieving good postoperative uncorrected VA by inserting spherical IOLs alone is not promising. Toric IOLs are being used to address this issue.

Spectacle dependency greatly affects the quality of life (QOL) after surgery. Toric IOLs are expected to reduce distance vision spectacle dependency after surgery by reducing astigmatism. However, mild astigmatism reportedly improves the uncorrected near VA (UNVA). ${ }^{3}$ Therefore, it is interesting to see how toric IOLs affect near vision spectacle dependency.

The aim of this study was to evaluate the visual performance and postoperative vision-related QOL in patients implanted with toric IOLs. We compared the patients implanted with toric IOLs bilaterally and the patients, who had the same degree of preoperative corneal astigmatism as that of the control group, implanted bilaterally with non-toric IOLs made of the same material. Distance and near $(50$ and $30 \mathrm{~cm}$, 
respectively) corrected and uncorrected VA and contrast sensitivity with and without glare were first measured to evaluate the visual function of toric IOL inserted eyes. We then analyzed the responses to the 25-item National Eye Institute Visual Function Questionnaire (NEI VFQ-25) and the rate of distance and near spectacle dependency to evaluate postoperative vision-related QOL in patients implanted with toric IOLs.

\section{Patients and methods}

\section{Patients}

This case-control study included patients who underwent bilateral cataract surgery at the Department of Ophthalmology, Tsukazaki Hospital between April 2009 and June 2014. The patients were implanted with either toric or non-toric IOLs made of the same material and design. The toric group received SN6AT series (Alcon Inc., Fort Worth, TX, USA) IOLs (SN6AT3-SN6AT9; Alcon Inc.) bilaterally, and the non-toric group received SN60WF (Alcon Inc.). We included only patients expected to achieve normal vision, and the patients with ocular diseases that impair the visual function except cataract were excluded.

The two groups were matched to have equivalent preoperative corneal astigmatism power. Specifically, both the groups were stratified by every $\pm 0.2 \mathrm{D}$ from the mean power, and the same number of samples was randomly selected, so that both groups had equivalent preoperative corneal astigmatism power. As a result of this matching, we had 103 subjects in each group to be used for statistical analysis.

\section{Preoperative examination}

Prior to surgery, all patients received the following examination, including evaluations of the axial length, radius of corneal curvature, corneal astigmatism, pupil size, refractive status, ocular aberrometry, distance VA, near VA and contrast sensitivity, an anterior segment evaluation using a slit lamp and fundoscopy. We measured the axial length, radius of corneal curvature, corneal astigmatism, refractive status, VA and contrast sensitivity twice within 2 months before cataract surgery, and then used the average. The quality of vision was evaluated using the Japanese version of the NEI VFQ-25. ${ }^{4}$ Interviews using VFQ-25 were conducted by skilled nurses or technicians in a face-to-face manner.

Corrected distance VA (CDVA) and uncorrected distance VA (UDVA) were measured at $5.0 \mathrm{~m}$ distance. Corrected near VA (CNVA) and UNVA were measured at $0.3 \mathrm{~m}$ distance. UDVA, CDVA, UNVA and CNVA values were measured using the decimal VA chart, and then the measured decimal
VA values were converted to the logarithm of the minimum angle of resolution scale. Axial length was measured by IOL Master (Carl Zeiss, Oberkochen, Germany) and AL-3000 (TOMEY, Nagoya, Japan). Radius of corneal curvature, corneal astigmatism and refractive status were measured by KR-8900 (Topcon, Tokyo, Japan). Contrast sensitivity (with/without glare) was measured by CGT-1000 (Takagi Seiko, Nakano, Japan). Pupil size and ocular aberrometry were measured by KR-1W (Topcon). All examinations and data acquisition were carried out by skilled technicians.

\section{Surgical procedures and IOLs}

Six experienced surgeons performed the cataract surgeries. The surgical procedure was conducted as follows: topical anesthesia, the creation of $2.8 \mathrm{~mm}$ temporal corneal incision, $5.0 \mathrm{~mm}$ continuous curvilinear capsulorhexis, phacoemulsification and aspiration of lens material and IOL implantation using an IOL injector. The patients were implanted with either SN60WF or SN6AT series IOL. We used the personal surgically induced astigmatism value to determine the lens model and axis location. Axis deviation of toric IOL was measured at 1 week after surgery. We repositioned the IOL when the axis deviation exceeded $10^{\circ}$.

\section{Postoperative examination}

We measured the CDVA, UDVA, CNVA, UNVA and contrast sensitivity (with/without glare) twice (at postoperative weeks 10 and 14) and used the average. Pupil size and ocular aberrometry were measured 14 weeks after surgery. The VFQ-25 and spectacle dependency were evaluated 18 weeks after surgery. The measurements from right eyes were used to evaluate VA and contrast sensitivity.

\section{Statistical analyses}

The statistical analyses were performed using a commercially available software program (JMP, version 10.0; SAS Institute Inc., Cary, NC, USA). Statistical significance was defined as two-tailed $P$-value $<0.05$.

\section{Ethics statement}

The procedures used in this study conformed to the tenets of the Declaration of Helsinki and were approved by the Ethics Committee of Tsukazaki Hospital. Signed informed consent was obtained from all patients after they were informed of the procedures. This study is registered as UMIN000006852: "Comparison between toric and non-toric intraocular lens implantation in patients approved for toric intraocular lens implantation." 


\section{Results}

Table 1 gives a summary of the two groups. There was no significant difference in the mean age between the toric and non-toric groups (72.25 and 73.69 years, respectively). There was also no significant difference in preoperative corneal astigmatism (the mean cylinder power of both eyes) and subjective astigmatism between the two groups. The postoperative subjective astigmatism was significantly lower in the toric group $(0.84 \mathrm{D})$ than the non-toric group $(1.42 \mathrm{D})$. No significant difference was found in the postoperative spherical equivalent and the axis of subjective astigmatism.

Figure 1 shows the results of postoperative VA in both groups. UDVA was significantly better in the toric group and U50 cmVA was significantly better in the non-toric group. There were no statistically significant differences in CDVA, C50 cmVA, U30 cmVA or C30 cmVA between the two groups. Figure 2 shows a comparison of cumulative postoperative UDVA between the two groups. About 70\% of the patients in the toric group achieved UDVA of 20/20 or better while only about $50 \%$ did so for the non-toric group. Table 2 shows the findings of postoperative contrast sensitivity with and without glare. At all frequencies both with and without glare, there was no significant difference in contrast sensitivity between the two groups.

Table 3 shows the findings of postoperative spectacle dependency in both the groups. Spectacle dependency was defined as the percentage of subjects who always or occasionally used eyeglasses. The rate of distance spectacle dependency was significantly lower in the toric group (19.4\%) compared to the non-toric group (66.6\%). No significant difference was found in the rate of near spectacle dependency (toric group: $88.3 \%$, non-toric group: $86.4 \%$ ). Table 4 shows the postoperative scores of the NEI VFQ-25 of both the groups. There were no significant differences in any question between the two groups.

\section{Discussion}

In this study, we compared the visual performance of patients implanted with toric IOLs and non-toric IOLs. UDVA was significantly better in the toric IOL implanted eyes than the non-toric IOL implanted eyes, whereas near VA at $50 \mathrm{~cm}$ was significantly worse in the toric IOL implanted eyes than the non-toric IOL implanted eyes. No significant difference was found in near VA at $30 \mathrm{~cm}$ between the two groups. In addition, there were no significant differences in corrected VA and contrast sensitivity between the two groups. With respect to the postoperative QOL in patients implanted with toric IOLs bilaterally, the rate of distance spectacle dependency in patients implanted with toric IOLs bilaterally was significantly lower than those implanted with non-toric IOLs bilaterally. There were no significant differences in the rate of near spectacle dependency as well as the scores of VFQ-25 between the two groups.

Regarding uncorrected VA, the distance VA of the toric IOL implanted eyes was significantly better than that of the non-toric IOL implanted eyes, whereas $50 \mathrm{~cm} \mathrm{VA}$ of the toric group was significantly inferior to that of the non-toric group, and no difference was observed in $30 \mathrm{~cm}$ VA between the two groups. The primary aim of toric IOL implantation is to reduce astigmatism of an entire eye by creating astigmatism in the eye which offsets the corneal astigmatism, and the present study also consistently showed that the postoperative subjective astigmatism of the toric group was lower than that of the non-toric group. In this study, UDVA of the toric IOL implanted eyes was better than that of the non-toric IOL implanted eyes, which confirms the primary feature of toric IOLs and a finding that is consistent with the previous

Table I Summary of both the groups

\begin{tabular}{|c|c|c|c|}
\hline & Toric & Non-toric & $P$-value \\
\hline IOL & SN6AT3-9 & SN60WF & \\
\hline $\mathrm{n}$ & 103 & 103 & \\
\hline Age (years) & $72.25(6.78)^{\mathrm{a}}$ & $73.69(7.18)^{\mathrm{a}}$ & $0.1411^{b}$ \\
\hline Preoperative corneal astigmatism (D) ${ }^{c}$ & I.I $33(0.444)^{\mathrm{a}}$ & I. I $27(0.4 \text { I })^{\mathrm{a}}$ & $0.9181^{d}$ \\
\hline Postoperative spherical equivalent (D) & $0.089(0.492)^{\mathrm{a}}$ & $-0.015(0.525)^{\mathrm{a}}$ & $0.1433^{b}$ \\
\hline Postoperative subjective astigmatism (D) ${ }^{c}$ & $0.84(0.442)^{\mathrm{a}}$ & $1.42(0.698)^{\mathrm{a}}$ & $<0.000 \mathrm{I}^{\mathrm{b}}$ \\
\hline \multirow[t]{4}{*}{ Axis of postoperative subjective astigmatism ${ }^{c, e}$} & WTR: 14 & WTR: 17 & $0.8996^{f}$ \\
\hline & Obl: 15 & Obl: 10 & \\
\hline & ATR: 54 & ATR: 69 & \\
\hline & None: 20 & None: 7 & \\
\hline
\end{tabular}

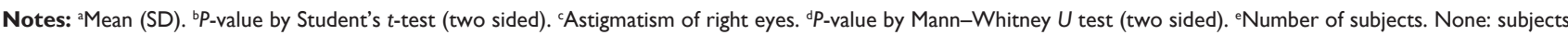
with cylinder power $<0.5 \mathrm{D}$. ${ }^{\mathrm{f}} \mathrm{P}$-value by chi-squared test (WTR/ATR ratio).

Abbreviations: ATR, against the rule astigmatism; IOL, intraocular lens; Obl, oblique astigmatism; WTR, with the rule astigmatism. 
UDVA

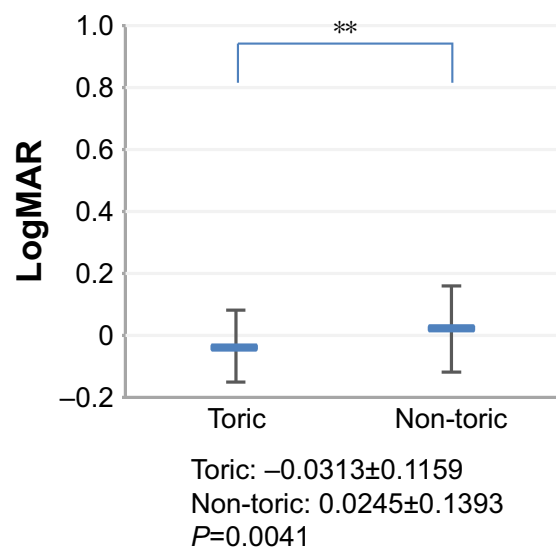

CDVA

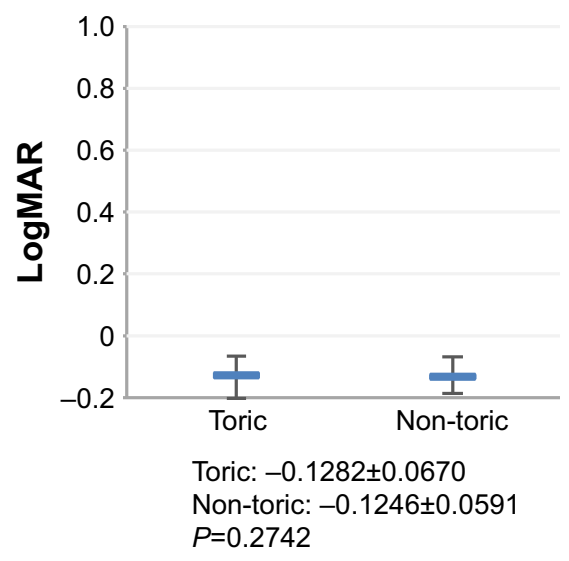

U50cmVA

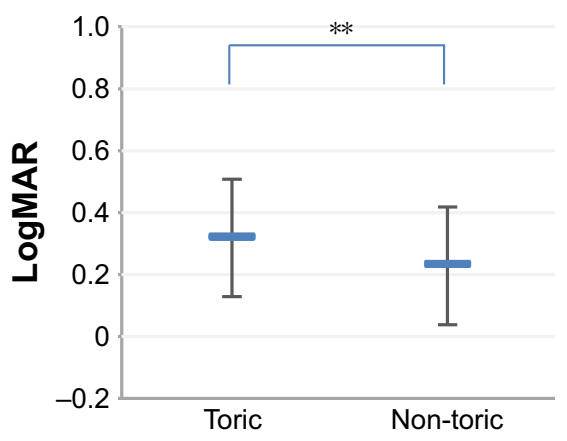

Toric: $0.3226 \pm 0.1901$

Non-toric: $0.2346 \pm 0.1901$

$P=0.0034$
U30cmVA

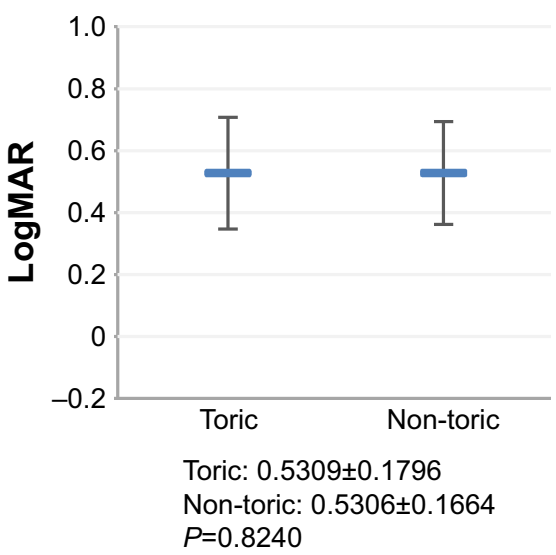

C30cmVA
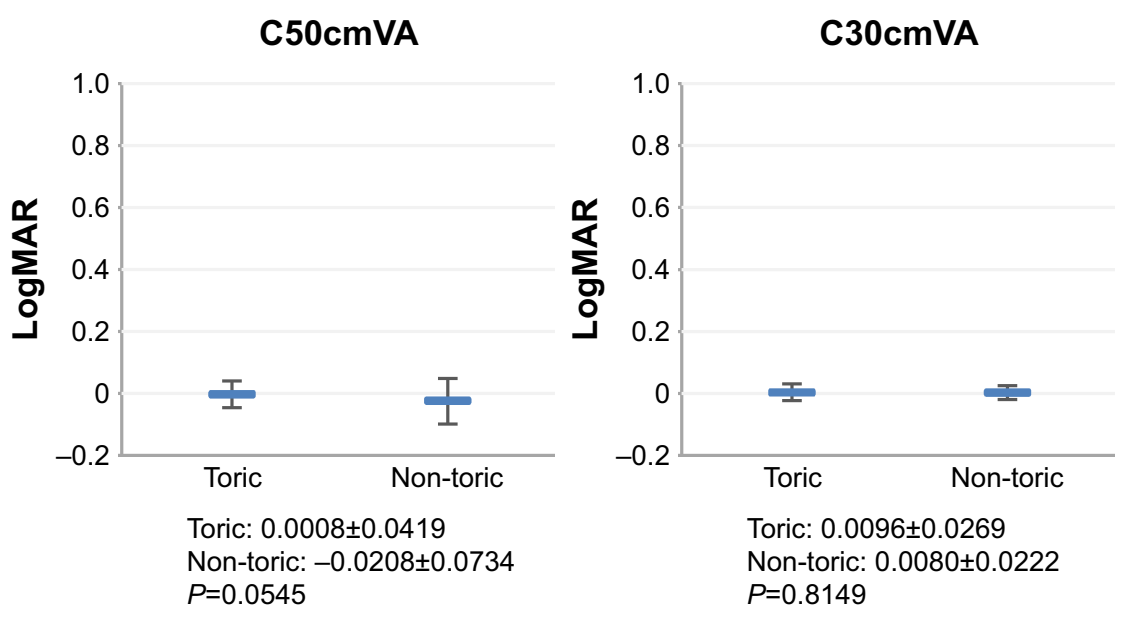

Figure I Uncorrected and corrected VA of the toric and non-toric groups (mean $\pm S D$ ).

Notes: The $P$-values were determined using the Mann-Whitney $U$ test. $* * P<0.01$.

Abbreviations: CDVA, corrected distant VA; LogMAR, logarithm of the minimum angle of resolution; UDVA, uncorrected distant VA; VA, visual acuity.

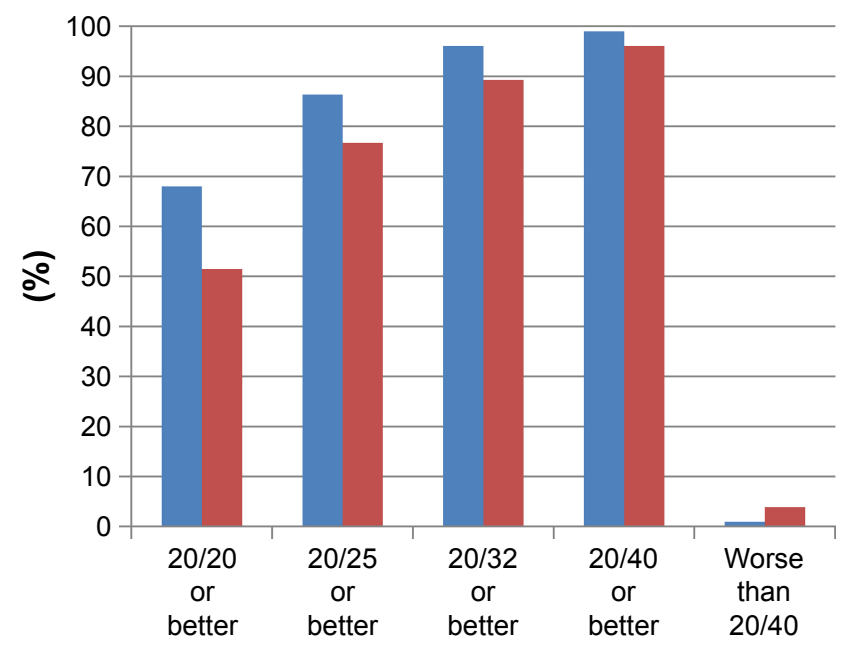

Toric $\square$ Non-toric

Figure 2 Cumulative UDVA, toric group vs non-toric group. Abbreviation: UDVA, uncorrected distant visual acuity. reports. ${ }^{5-7}$ Our results also showed that uncorrected $50 \mathrm{~cm} \mathrm{VA}$ was better in the non-toric group than the toric group. To our knowledge, there have been no previous reports concluding that the UNVA of toric IOL implanted eyes is inferior to that of the non-toric IOL implanted eyes; however, increase in depth of focus in regular astigmatism has been reported. ${ }^{3,8,9}$ Therefore, the fact that the postoperative astigmatism in non-toric IOL implanted eyes occurs more frequently than the toric group may have contributed to better uncorrected $50 \mathrm{~cm}$ VA in the non-toric group. As for contrast sensitivity, no significant difference was found between the toric and non-toric groups. Our results on the contrast sensitivity of the toric and non-toric implanted eyes having similar level of corneal astigmatism were consistent with previous studies, which showed no significant difference between the two groups.$^{10}$ Previously we reported that the contrast sensitivity 
Table 2 Contrast sensitivity without/with glare

\begin{tabular}{|c|c|c|c|}
\hline $\begin{array}{l}\text { Optotype } \\
\text { size }\end{array}$ & Toric & Non-toric & $P$-value ${ }^{a}$ \\
\hline \multicolumn{4}{|c|}{ A. Contrast sensitivity without glare } \\
\hline 7 & $0.318(0.119)$ & $0.333(0.122)$ & 0.2521 \\
\hline 10 & $0.163(0.108)$ & $0.168(0.107)$ & 0.4351 \\
\hline 16 & $0.085(0.073)$ & $0.085(0.056)$ & 0.2670 \\
\hline 25 & $0.049(0.037)$ & $0.050(0.030)$ & 0.4235 \\
\hline 40 & $0.038(0.028)$ & $0.038(0.022)$ & 0.6695 \\
\hline 63 & $0.033(0.028)$ & $0.028(0.013)$ & 0.1943 \\
\hline \multicolumn{4}{|c|}{ B. Contrast sensitivity with glare } \\
\hline 7 & $0.385(0.105)$ & $0.397(0.102)$ & 0.3767 \\
\hline 10 & $0.235(0.125)$ & $0.244(0.131)$ & 0.6461 \\
\hline 16 & $0.133(0.102)$ & $0.136(0.105)$ & 0.8074 \\
\hline 25 & $0.086(0.072)$ & $0.089(0.079)$ & 0.9308 \\
\hline 40 & $0.061(0.042)$ & $0.064(0.049)$ & 0.3366 \\
\hline 63 & $0.052(0.037)$ & $0.044(0.027)$ & 0.1614 \\
\hline
\end{tabular}

Notes: Mean (SD). aP-value by Mann-Whitney $U$ test (two-sided).

of the patients implanted with diffractive multifocal IOLs was inferior to that of the patients implanted with monofocal IOLs of the same material; ${ }^{11}$ however, such contrast sensitivity loss was not observed with toric IOLs in the present study.

The rate of distance spectacle use was significantly lower in patients implanted with toric IOLs bilaterally than those implanted with non-toric IOLs bilaterally. This result seems to reflect that UDVA of the toric group is better than that of the non-toric group. In addition, this finding is consistent with many of the previous reports ${ }^{5-7,10,12}$ and shows the clinical usefulness of toric IOLs. On the other hand, there was no significant difference in the rate of near spectacle use between the two groups; the rate was about $90 \%$ for both the groups. The VA at $50 \mathrm{~cm}$ was better in the non-toric group than the toric group; however, the increase in depth of focus is unlikely to have any effect on decreasing the near spectacle dependency. With respect to the VFQ-25 scores, there were no significant differences between the two groups. VFQ-25 is a quality of vision questionnaire ${ }^{13}$ and has been utilized for the evaluation of a variety of ocular diseases. ${ }^{14-16}$
The Japanese version of VFQ-25 has been validated by Suzukamo et al. ${ }^{4}$ This report seems to be the first study comparing the responses to VFQ-25 between patients with bilateral implantation of toric IOLs and the matched patients with bilateral implantation of non-toric IOLs. In our previous study, we evaluated the VFQ-25 responses of the patients implanted with diffractive multifocal IOLs bilaterally and the matched patients implanted with monofocal IOLs bilaterally ${ }^{11}$ and concluded that the patients with multifocal IOLs scored significantly less on nighttime driving than the counterpart; however, such a difference in the score was not observed between the toric and non-toric groups in this study.

There are options other than toric IOL implantation to correct astigmatism in cataract surgery. The simplest method is a steep meridian incision. This technique is very effective for correcting mild astigmatism. However, it is impossible to correct moderate-strong astigmatism. Mingo-Botín et al $^{17}$ and Hirnschall et al ${ }^{18}$ compared toric IOL implantation with peripheral corneal relaxing incision (PCRI) and reported that the predictability of postoperative astigmatism is inferior in PCRI. Moreover, PCRI has problems such as foreign body sensation and regression of astigmatism reduction. Astigmatic keratotomy $(\mathrm{AK})$ is another alternative for correcting astigmatism. Titiyal et al reported that the astigmatic correction performance of $\mathrm{AK}$ is equivalent to that of toric $\mathrm{IOL}$ implantation. ${ }^{19}$ However, $\mathrm{AK}$ is more invasive to the cornea and can cause corneal ectasia. Furthermore, AK requires special instruments. For the above reasons, we consider that toric IOL implantation is the best option to correct moderatestrong astigmatism in most institutions.

One of the limitations of the present study is that the study was a retrospective study. The patients were not randomly selected to be put in one of the two groups, the toric group or the non-toric group, to receive either IOL. In recent years, we have been primarily using toric IOLs for our patients when better visual performance can be expected by the use of toric

Table 3 Postoperative spectacle dependency

\begin{tabular}{l|l|l|l|l|l}
\hline & Never (n) & Occasionally (n) & Always (n) & $\begin{array}{l}\text { Spectacle } \\
\text { dependency (\%) }\end{array}$ & $P$-value \\
\hline Distance & & & & & 0.0003 \\
$\quad$ Toric & 83 & 9 & 11 & 19.4 & \\
Non-toric & 35 & 7 & 61 & 66.0 & 0.3514 \\
Near & & & 68 & 88.3 & \\
$\quad$ Toric & 12 & 23 & 74 & 86.4 & \\
Non-toric & 14 & 15 & & \\
\hline
\end{tabular}

Note: The $P$-values were determined using the chi-squared test. 
Table 4 Postoperative scores of the NEI VFQ-25

\begin{tabular}{|c|c|c|c|}
\hline & Toric & Non-toric & $P$-value \\
\hline Composite & $89.9(0.6)$ & $89.9(0.8)$ & $P=0.326 \mathrm{I}$ \\
\hline General health & $60.7(1.6)$ & $60.9(1.6)$ & $P=0.9588$ \\
\hline General vision & $79.6(I . I)$ & $78.4(1.3)$ & $P=0.6220$ \\
\hline Ocular pain & 88.9 (1.5) & 90.5 (I.4) & $P=0.4294$ \\
\hline Near vision & $90.5(1.2)$ & $92.0(1.5)$ & $P=0.135 \mathrm{I}$ \\
\hline Distance vision & $93.2(1.0)$ & $92.6(I . I)$ & $P=0.8049$ \\
\hline Social function & $95.6(0.8)$ & $95.6(0.9)$ & $P=0.5638$ \\
\hline Mental health & $94.8(0.9)$ & $94.9(1.3)$ & $P=0.0930$ \\
\hline Role limitation & $95.9(0.7)$ & $95.7(1.0)$ & $P=0.2254$ \\
\hline Dependency & $98.0(0.6)$ & $97.9(0.7)$ & $P=0.3707$ \\
\hline Driving & 91.1 (I.5) & $90.4(1.5)$ & $P=0.8354$ \\
\hline Color vision & $96.8(0.9)$ & $97.3(0.9)$ & $P=0.693 \mathrm{I}$ \\
\hline Peripheral vision & $94.2(1.2)$ & $92.7(1.5)$ & $P=0.830 \mathrm{I}$ \\
\hline
\end{tabular}

Notes: The shown values represent the mean (SD) of 103 patients in each group, except for the questions regarding driving and color vision. For the question on driving, the value was derived from the responses of 58 patients in the toric group and 64 patients in the non-toric group. For the question on color vision, the value was derived from the responses of 102 patients in the toric group and 100 patients in the non-toric group. The $P$-values were determined using Mann-Whitney $U$ test (two sided).

Abbreviation: NEI VFQ-25, 25-item National Eye Institute Visual Function Questionnaire.

IOLs. Therefore, most of the patients included in the nontoric group in this study were those who underwent cataract surgery before the SN6AT series IOLs became available at our clinic; so, the timing of cataract surgery slightly differs between the toric group and the non-toric group. However, since there have been no major changes in the surgical procedures as well as surgeons at our clinic, the difference in timing of the surgeries is unlikely to influence the study results.

\section{Conclusion}

We compared the visual performance in patients with corneal astigmatism who were implanted with toric or non-toric IOL. The postoperative UDVA was better in the toric group, while the uncorrected VA at $50 \mathrm{~cm}$ was better in the non-toric group. In addition, the patients implanted with toric IOLs bilaterally showed reduced distance spectacle dependency compared to those implanted with non-toric IOLs bilaterally. There were no significant differences in contrast sensitivity and the VFQ-25 scores between the two groups. Toric IOL offers more clinical benefits than non-toric IOL as long as IOL power and placement orientation are appropriate, thus the use of toric IOLs can be highly recommended for patients with corneal astigmatism.

\section{Data sharing statement}

The datasets are available in the "figshare" repository, https:// figshare.com/articles/data of toric IOL/1335752.

\section{Acknowledgment}

This manuscript was edited by the English editing service, Enago (https://www.enago.com/).

\section{Author contributions}

TY, HT and YK designed the study. TY and HT wrote the manuscript. TY, HT and KT contributed to analysis and interpretation of data. $\mathrm{KT}, \mathrm{ZO}, \mathrm{HI}$ and $\mathrm{YK}$ assisted in preparation of the manuscript. All authors contributed to data analysis, drafting and revising the article, gave final approval of the version to be published, and agree to be accountable for all aspects of the work.

\section{Disclosure}

The authors report no conflicts of interest in this work.

\section{References}

1. Ferrer-Blasco T, Montés-Micó R, Peixoto-de-Matos SC, GonzálezMéijome JM, Cerviño A. Prevalence of corneal astigmatism before cataract surgery. J Cataract Refract Surg. 2009;35(1):70-75.

2. Hoffmann PC, Hütz WW. Analysis of biometry and prevalence data for corneal astigmatism in 23,239 eyes. J Cataract Refract Surg. 2010;36(9): 1479-1485.

3. Savage H, Rothstein M, Davuluri G, El Ghormli L, Zaetta DM. Myopic astigmatism and presbyopia trial. Am J Ophthalmol. 2003;135(5): 628-632.

4. Suzukamo Y, Oshika T, Yuzawa M, et al. Psychometric properties of the 25-item National Eye Institute Visual Function Questionnaire (NEI VFQ-25), Japanese version. Health Qual Life Outcomes. 2005;3:65.

5. Holland E, Lane S, Horn JD, Ernest P, Arleo R, Miller KM. The AcrySof Toric intraocular lens in subjects with cataracts and corneal astigmatism: a randomized, subject-masked, parallel-group, 1-year study. Ophthalmology. 2010;117(11):2104-2111.

6. Kessel L, Andresen J, Tendal B, et al. Toric intraocular lenses in the correction of astigmatism during cataract surgery: a systematic review and meta-analysis. Ophthalmology. 2016;123(2):275-286.

7. Visser N, Bauer NJ, Nuijts RM. Toric intraocular lenses: historical overview, patient selection, IOL calculation, surgical techniques, clinical outcomes, and complications. J Cataract Refract Surg. 2013;39(4): 624-637.

8. Sawusch MR, Guyton DL. Optimal astigmatism to enhance depth of focus after cataract surgery. Ophthalmology. 1991;98(7):1025-1029.

9. Singh A, Pesala V, Garg P, Bharadwaj SR. Relation between uncorrected astigmatism and visual acuity in pseudophakia. Optom Vis Sci. 2013;90(4):378-384.

10. Visser N, Beckers HJ, Bauer NJ, et al. Toric vs aspherical control intraocular lenses in patients with cataract and corneal astigmatism: a randomized clinical trial. JAMA Ophthalmol. 2014;132(12):1462-1468.

11. Yamauchi T, Tabuchi H, Takase K, et al. Comparison of visual performance of multifocal intraocular lenses with same material monofocal intraocular lenses. PLoS One. 2013;8(6):e68236.

12. Data for FDA approval. Available from: http://www.accessdata.fda. gov/cdrh_docs/pdf/P930014S015b.pdf

13. Mangione CM, Lee PP, Gutierrez PR, et al. Development of the 25-item National Eye Institute Visual Function Questionnaire. Arch Ophthalmol. 2001;119(7):1050-1058.

14. Lin IC, Wang IJ, Lei MS, Lin LL, Hu FR. Improvements in visionrelated quality of life with AcrySof IQ SN60WF aspherical intraocular lenses. J Cataract Refract Surg. 2008;34(8):1312-1317. 
15. Hyman LG, Komaroff E, Heijl A, et al. Treatment and vision-related quality of life in the early manifest glaucoma trial. Ophthalmology. 2005; 112(9):1505-1513.

16. Bradley EA, Sloan JA, Novotny PJ, et al. Evaluation of the National Eye Institute visual function questionnaire in Graves' ophthalmopathy. Ophthalmology. 2006;113(8):1450-1454.

17. Mingo-Botín D, Muñoz-Negrete FJ, Won Kim HR, et al. Comparison of toric intraocular lenses and peripheral corneal relaxing incisions to treat astigmatism during cataract surgery. J Cataract Refract Surg. 2010; 36(10):1700-1708.
18. Hirnschall N, Gangwani V, Crnej A, et al. Correction of moderate corneal astigmatism during cataract surgery: toric intraocular lens versus peripheral corneal relaxing incisions. J Cataract Refract Surg. 2014;40(3): 354-361.

19. Titiyal JS, Khatik M, Sharma N, et al. Toric intraocular lens implantation versus astigmatic keratotomy to correct astigmatism during phacoemulsification. J Cataract Refract Surg. 2014;40(5):741-747.

\section{Publish your work in this journal}

Clinical Ophthalmology is an international, peer-reviewed journal covering all subspecialties within ophthalmology. Key topics include: Optometry; Visual science; Pharmacology and drug therapy in eye diseases; Basic Sciences; Primary and Secondary eye care; Patient Safety and Quality of Care Improvements. This journal is indexed on

Submit your manuscript here: http://www.dovepress.com/clinical-ophthalmology-journal

\section{Dovepress}

PubMed Central and CAS, and is the official journal of The Society of Clinical Ophthalmology (SCO). The manuscript management system is completely online and includes a very quick and fair peer-review system, which is all easy to use. Visit http://www.dovepress.com/ testimonials.php to read real quotes from published authors. 